\title{
The influence of conference calls' semantic characteristics on the company market performance: Text analysis
}

\author{
Elena Fyodorova ${ }^{\mathrm{a}, \mathrm{b}, *}$, Ruslan Sayakhov ${ }^{\mathrm{b}}$, \\ Igor Demin $^{a}$, Dmitriy Afanasyev c, $§$ \\ a Financial University under the Government of the Russian Federation, Moscow, Russian Federation \\ ${ }^{\mathrm{b}}$ HSE University, Moscow, Russian Federation \\ c JSC "Greenatom", Moscow, Russian Federation
}

\begin{abstract}
The purpose of the study is to find out the influence of semantic (emotional coloring, length and complexity of the text) and thematic features (environmental, corporate-social and legal context) of conference calls with market analysts and investors on future company performance (CAR) and analysts' recommendation for the share. The empirical framework of the research includes annual conference calls of public companies on the Moscow (MOEX) and London Stock Exchanges (LSE) from 2015 to 2019. The research methodology is based on the semantic analysis of the call text by using the linguistic dictionaries NRC 2010 and Corporate Social Responsibility 2016. The results of the study illustrate the significant impact of textual features of the conference call (the general tone of the call, the tone of management and the negative tone of analysts, the length and complexity of the text) on the abnormal stock returns (for 3, 14, 30 days). This relation is consistent for companies of both stock exchanges, but diverges in terms of the influence of the thematic characteristics of the call that can be explained by the mandatory disclosure of this information by European public companies (ESG Reports), as opposed to voluntary publication by Russian companies. The results can be applied both by the management of public companies in order to improve companies' attractiveness (perception and transparency) and its market value in the short and medium-term period, and by investors to manage effectively the portfolio by predicting the future dynamics of the company's share price after a conference call based on semantic tone and thematic features.
\end{abstract}

Keywords: conference call, semantic analysis, thematic analysis, non-financial information, neural network MLP, linguistic glossaries.

JEL classification: G32, G41.

\footnotetext{
* Corresponding author, E-mail address: ecolena@mail.ru

$\S$ The point of view of Dmitriy Afanasyev does not represent the official position of JSC "Greenatom" and may not coincide with it.
}

(C) 2019 Non-profit partnership "Voprosy Ekonomiki". This is an open access article distributed under the terms of the Attribution-NonCommercial-NoDerivatives 4.0 (CC BY-NC-ND 4.0). 


\section{Introduction}

The key factors in forging a company's attractiveness, image and market value are two instruments: the firm's financial results that are published on a periodic base and its strategic outlook and guidance in the long term. On the one hand, analysts and institutional investors determine the fair value of the company, which is reflected in the market share price or in their investment decisions, as well as in the recommendations regarding its attractiveness ("buy", "neutral", "sell"), based on the periodic operating and financial performance of the company. On the other hand, the published financial results and company press releases can be a trigger to eliminate the information asymmetry between company management and external market participants (investors, analysts, the state) that makes financial markets most effective in terms of the economic theory (agent theory). One of the key and reputable tools for mitigating the information asymmetry between the company and the financial market is officially published information (business efficiency and growth outlook, dividend and social policy, compliance with environmental standards and emission reductions, ensuring staff motivation) in the public domain by management through new information channels: press releases of operating and financial results, CEO and Board of Directors (BoD) Letters, investor conference calls, etc. The given information allows for the efficient optimization of expectations of all market agents regarding the firm opportunities and perspectives that will affect inevitably the market share price and performance since this information is fundamental and public for all financial markets and investors.

The purpose of the research is to find out and estimate the influence of semantic and thematic features of annual conference calls (company management with analysts and investors) on a company's future market performance. The relevance of this survey is validated, on the one hand, by the lack of scientific articles in this field among public firms from developing countries and Europe and the absence of research on the impact of conference calls' linguistics and topics on a company's future performance. On the other hand, the significance of this paper is justified by the increasing popularity of new communication channels between company management and investors and market bank analysts (CEO and BoD Letters, conference calls, investor day releases).

The subject that is related to the influence of non-financial information becomes more popular and relevant not only for foreign researchers but also for Russian economists. In recent work in this field, Kelchevskaya et al. (2017) built a regression model for a sample of 18 Russian public companies and found that the disclosure of corporate social responsibility (CSR) information has a significant impact on the cost of equity and investment attractiveness of companies. Researchers' results indicate the importance and necessity of disclosure of the non-financial information. In an earlier study, Kuznetsova and Maslova (2013) also discovered a strong relation between the disclosure of corporate social responsibility information and company transparency (legitimacy of doing business) that are also associated with its attractiveness and positive perceptions among current and potential investors. Udaltsov and Tikhonova (2013) built the information transparency index for companies according to a sample of 34 Russian public companies, which turned out to be related significantly and unidirectionally to firms' investment strategy and 
the attractiveness of the company for investors. Russian economists (Fyodorova et al., 2017, 2019) have conducted the first attempt to evaluate the role and significance of non-financial reporting in the sample of CEO and BoD Letters. The authors have failed to identify a significant relationship between narcissism, the emotional tone of official letters and the future financial results of the company. However, they have discovered a significant relationship between the linguistic characteristics of Letters and the company's choice of capital structure. In contrast, alternative papers devoted to the analysis of non-financial information (press releases, conference calls, etc.) on a sample of Russian and CIS companies have not yet been undertaken over the past decade.

The basis of the research (data sample) conducted is conference calls (selector meetings by telephone). Conference calls are periodic teleconferences (quarterly/ semi-annual/annual) led by management of public companies with investment banking analysts as well as private and institutional investors and held in order to discuss operational and financial results. They also explain briefly the company's strategy next quarter/year and enable a short airing of questions about the company that interest analysts and investors. The conference call is provided by the management of the company on a voluntary basis, but: (1) an increasing number of public companies from emerging markets (including EMEA) introduce this principle of communication with investors in order to increase transparency and trust for the firm, to strengthen the attractiveness and competitiveness of the company among industry peers. This fact is reflected in the dynamics of the number of conference calls that were held both for a certain company and for companies in the market as a whole (the growth in the number of companies conducting conference calls); (2) the call is regulated by the company in advance (published on the company's website calendar and brought to analysts and brokers beforehand) and allows any interested investors to take part in the call without restriction; (3) the results of the call (transcripts) together with the question-answer part (Q\&A) are available in the Bloomberg/Thomson Reuters financial monitors in the public domain within 2-3 days after it has taken place.

Organized teleconferences of the company's management with market analysts have become a pivotal avenue of public information disclosure by the share issuer concerned in recent years. The main objective of this communication channel with the financial market is to clarify the meaning of the operational and financial results that the company periodically discloses on a quarterly basis. In many cases, financial results provided by a company fail to indicate any correct and definite conclusions about the effectiveness of the firm's performance in the past period or its future growth prospects. This is only achieved through market analysts who act as mediators between the company management and investors by explaining information and addressing particularly pertinent questions.

It should be noted that each type of placed information (annual report, press release, operating results, RAS/IFRS statements) is traditionally published at different times. This eliminates the short-term effect of the publication of one reporting on another in terms of share price. However, a conference call involves wider topics and themes (without strict restrictions and a framework in the Q\&A section), and allows for efficient communication between management and investors on the topics of financial and operational results, ecology, investment and the dividend policy, etc. 
This article aims to illuminate whether there is an emotional and thematic differentiation in the conference call of public companies between its management and research analysts from different countries and stock exchanges, and whether these factors really affect the dynamics of the share price in the future or analysts' recommendations for certain equity.

\section{Literature review and research hypotheses}

Nowadays the management of public companies will use various strategies to manage a company's image and attempt to shape positive impressions. These strategies conceptually based on existing scientific literature can be classified in the following ways: semantic distortion of information (difficulty in text reading), rhetorical manipulation (using coherent and logical text), thematic distortion (using special vocabulary - maximum positive and minimum negative words, the bias of the tone and topic), visual distortion (visualized data and information presented), comparison of results with worse benchmarks (shift of analog companies to companies with worse performance - the bias), the choice of a limited number of financial and operational indicators in favor of the company side (disclosed to investors).

The motives and strategies of the company management for manipulating and distorting voluntarily disclosed information and reporting can be presented schematically in Fig. 1.

Most of the strategies can be actively applied by the company management and do not necessitate presenting distorted information to external participants, including investors. Some of them, however, are applicable to the disclosure and publication of textual information and the reporting (text perception, structural distortion, manipulation of subjects), while other strategies are used to present data in conference calls and company presentations (visual distortion, emotional and rhetorical manipulation). The feature of the presented strategies of media manipulation is the opportunity of its simultaneous application, which allows for multiplying the positive impression and growth opportunity of the company in the eyes of external participants (investors). Meanwhile, researchers (Courtis, 1998, 2004; Li, 2006; Davis et al., 2006) showed that the main instruments of distorting and embellishing the results involved "dimming" of bad news, namely the creation of complexity of text perception, thematic manipulation through introducing many positive words and neutral vocabulary instead of negative phrases (in samples of press releases and official appeals from the public company management to investors).

Nevertheless, rhetorical manipulation by means of sound perception of the tone and its color and the visual distortion of information through the creation of special presentation and reports structure have become very popular and important in financial markets these days. These instruments form new and modern communication channels between the company management and market participants. They allow drawing the viewer's focus exclusively on the positive characteristics and certain financials that the company wants to disclose and convey to investors and shareholders. As part of our theoretical and empirical analysis, we advance six hypotheses, presented below, that will be tested in the research. 


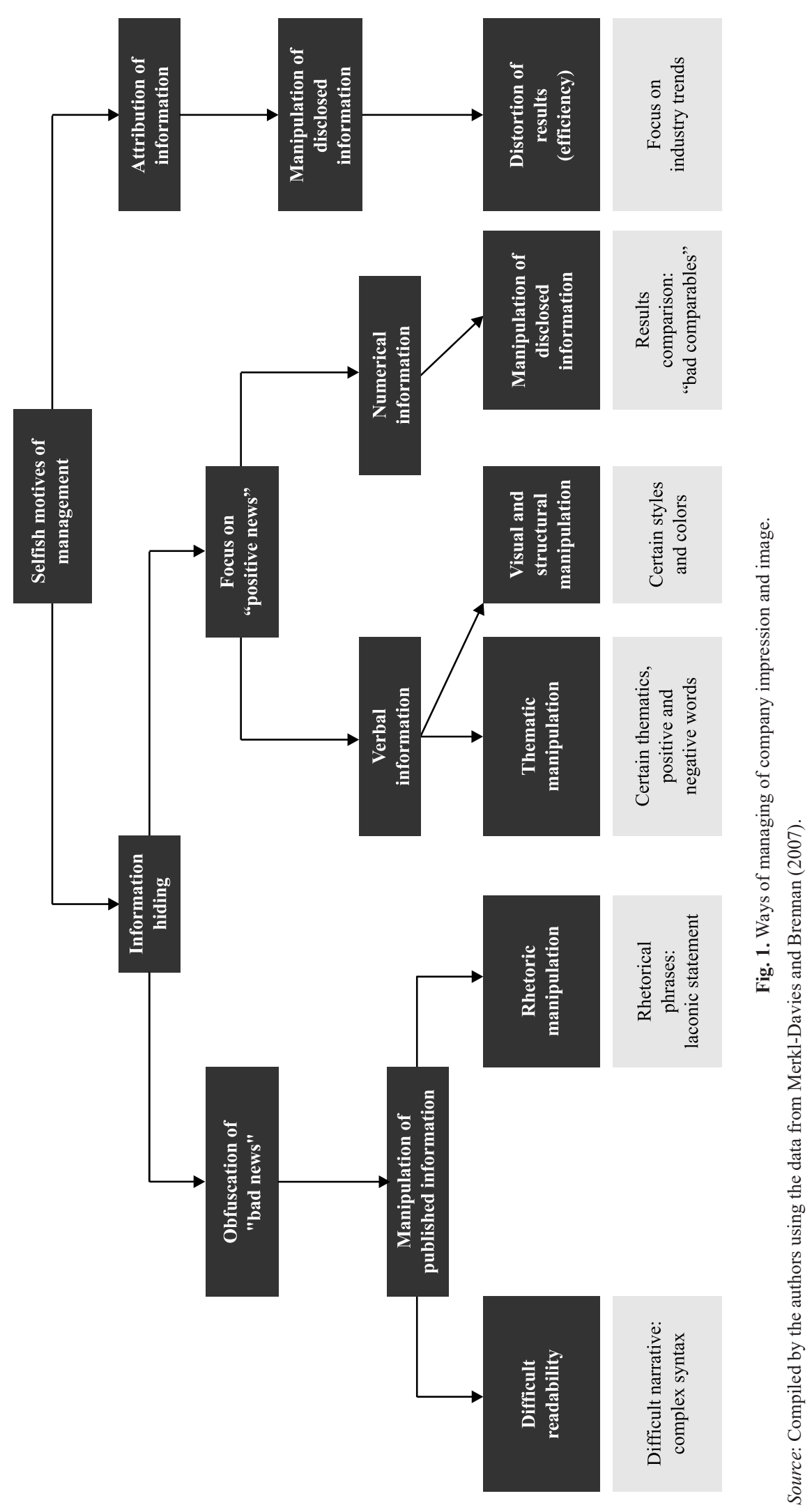


Hypothesis 1. The presence of a significant positive relationship between the conference call tone and the future excess share return of the company (CAR) in the short and medium terms.

This hypothesis assumes that the more positive the text tone, the more favorable the impression and mood created for readers (analysts and investors). Then they will subsequently revise upwards their expectations and recommendations concerning this company. In the framework of the study, the NetSent and PosSent variables will be used as the "semantic" (tonality) variables, and the formula description of them will be given below. Previously, this hypothesis was confirmed in earlier studies, which were devoted to the text tone of CEO and Board of Directors Letters as well as press releases according to the sample of USA companies of S\&P500, German and Russian public firms (Martinez-Blasco et al., 2015; Bannier et al., 2017; Patelli and Pedrini, 2014; Fyodorova et al., 2017). As part of the conference call research, hypothesis 1 was tested and confirmed in samples of public companies of USA and of Hong Kong Stock Exchange in 2005-2015 (Doran et al., 2012; Brockman et al., 2017).

Hypothesis 2. The presence of a significant negative relation between the negative tone of analysts and investors in the Q\&A part of the conference call and the change in the recommendation for this equity by investment analysts in the future ("buy", "neutral", "sell").

Since investment banking analysts and institutional investors are the information intermediaries between the company and the financial markets, it is assumed that the call tone used by participants reflects their impression and interest in certain equities and that this is replicated to change or maintain the recommendations in Equity Research after making the call: strictly sell (5), sell (4), hold (3), buy (2), strictly buy (1). Due to the weak efficiency of the financial market, the given information should be reflected in recommendations 30 days after the date of conference call as a minimum. Previously, hypothesis 2 was not tested in samples of conference calls, but in Jegadeesh et al. (2004), Martinez (2010), and Kontio (2016) the "analyst recommendation" variable was used jointly with the future financial and market results of USA, Finland and other European companies and as a result this variable turned out to be a significant explanatory factor. Currently, there are few papers in the field of the impact of analysts' recommendations on the future value of the company's share price. This does not allow us to make a general and accurate conclusion about the high correlation of these factors. However, brokers and traders generally tend to note that the change in the analyst's equity valuation has a high impact on the subsequent dynamics of the share price in the short term. For example, in Souček and Wasserek (2014), and Murg et al. (2014) the importance of the "analyst's valuation" variable was confirmed in a sample of European public companies in the short and medium term (up to 6 months).

Hypothesis 3. The future market performance of the company is more sensitive to the conference call tone of analysts and investors than to the tone of company management.

Indeed, the conference call tone and the general position of the company's management is biased in favor of creating a positive impression and a high image of the firm, while the position of analysts and investors, on the one hand, reflects the mean market sentiment, fair valuation and all relevant information about the company. On the other hand, analysts' valuations are the most objective since 
they are not attached to the position of the company. In other words, the represented hypothesis suggests that the tone of bank analysts is a better predictor of the future market and financial performance of the company than the tone and emotional coloring of the management text and speech.

This fact can be explained by the possibility of direct influence of analysts on the market and investors, in particular by changing the recommendation regarding certain equity, or by issuing public news with a negative or positive connotation after the completed conference call. The similar hypothesis was previously tested in Price et al. (2012) and Brockman et al. (2015), where the authors confirmed it in a sample of quarterly conference calls of American companies, but an opposite link was found in an empirical study by Brockman et al. (2017) in the sample of Hong Kong public companies for a later period (2005-2015).

Hypothesis 4. The existence of the significant negative link between the length, complexity of the text of the call with analysts (number of words, FOG index) and the future market performance of the company.

This hypothesis assumes that the conference call text should be concise, clear and simple. Further, that the company's management is not motivated to embellish and distort factual information at its disposal and so obscure a correct understanding of the overall picture for listeners and investors. It assumes that they will enable correct interpretation of the given text. If, on the other hand, a presentation is over-complex or characterized by wishful thinking, then analysts and investors may perceive this information as distorted or interpret it as a possible attempt at manipulation on the part of the company's management to "obscure" negative facts and news. This can undermine the dynamics of stocks in the short or medium term. Previously, this hypothesis was verified in Brockman et al. (2017) and Doran et al. (2012) devoted to the analysis and influence of the tonality of conference calls, and is also confirmed in samples of CEO Letters (Courtis, 2004; Li, 2008) for USA and Chinese companies, but was rejected in Fyodorova et al. (2017) in the sample of CEO Letters of 50 public Russian companies for 2010-2016.

Hypothesis $5 \mathrm{a}$. The degree of non-financial information disclosure during a call (ecology, social responsibility, protection of human rights, etc.) is significantly and positively related to the future excess return of the company share.

Hypothesis $5 b$. The degree of non-financial information disclosure during a call (ecology, social responsibility, protection of human rights, etc.) is significantly and negatively related to the forecast error regarding earnings per share (EPS surprise).

These hypotheses imply the significance and essentiality of non-financial information that is disclosed by companies on a voluntary basis and allows investors and analysts to take into account all risks and nuances as far as possible when they valuate the attractiveness of equities and build financial projections for the company's future. The given information should lead ultimately to an increase in the accuracy of the forecast (reduction in error) and the absence of surprise (the forecast error of analysts) in dividends and earnings per share. In earlier studies, these hypotheses were not tested in conjunction with the considered dependent variables (the forecast error and dividend surprise), since the applied dictionaries in this paper appeared relatively recently (2016-2018) and have not yet been tested in studies in this field, but the dependent variables are 
presented only in a limited sample of companies and usually only for the period up to 2012-2013.

Hypothesis 6 . The conference call tone of bank analysts, company management and thematic features of the conference call significantly differ between the companies of the Moscow and London Stock Exchanges.

The research conducted suggests that the semantic and linguistic features of the call conducted by the company's management can be perceived differently by analysts and investors of the European and Russian financial markets because: (1) there may be differences in the information efficiency of these markets; (2) the track record of these calls for companies of LSE is several times longer than for companies of the Moscow Stock Exchange. This can be reflected in a more conservative or emotional tone of European call participants in comparison to colleagues from the Russian financial market. Earlier, the similar hypothesis in the framework of conference calls has not been tested, but significant difference in tonality geographically was found in the sample of CEO Letters in the recent works (Craig and Brennan, 2012; Patelli and Pedrini, 2014).

The advanced hypotheses in this section will be tested using the econometric tools and machine learning (neural network; see the next section).

\section{Research methodology}

The main methodological and technical complication of the study is the analysis of textual information, namely the transcripts of management calls with analysts, since it is required to derive a vector of quantitative variables from qualitative data (text parameters), which describe it from the position of emotional coloring, tonality, complexity and subject. Previously, the surveys in this field and in general in the analysis of textual information and relation with financial variables were practically absent, since there was no suitable data tools for computer analysis and transformation of the data from a qualitative type to a quantitative one. However, modern methods of analysis of information have appeared with the development of computer technologies and new programming languages in recent years, and among them one of the most popular has become the method of "bag of words" (Fung et al., 2002; Wu et al., 2010, 2014). The key idea of this tool of text analysis is as follows: each of the texts (in this case, the text transcript of the conference call) is considered as an unordered set of words included in it. After the exclusion from composition of the "stop words" (prepositions, particles, etc.) the remaining words are evaluated on the basis of special dictionaries where terms have the characteristics of tonality, such as "positive", "negative", "surprise", etc. Thus, it seems possible to assess the general tone of the text based on its included words.

In the last decade, a significant number of such economic, financial, and news dictionaries have appeared based on the surveys of a large volume of press releases of companies' financial results, CEO Letters and BoD Letters, financial reports (10-K, 10-Q) of US and European companies. Applying these data, the researchers have built dictionaries of financial and economic topics with the assignment to words of certain emotional orientation and tonality. Principally, the original and modern dictionary will be used in the framework of this work, - NRC (National Research Council) — the advantage of that is, firstly, a higher number 
of words in the glossary (6468 terms instead 3916 terms in the vocabulary of Loughran and McDonald, 2014), and secondly, the opportunity of the assignment of 10 signs of emotional coloring of words ("trust", "sadness", "anger", "fear", "disgust", "positive", "negative", etc.) instead of 3 signs of tonality, as in earlier dictionaries, that gives the opportunity to expand the scope of current and further research. Demin et al. (2019) empirically approve that the financial and economic dictionary NRC is the most suitable and shows better analysis results than the dictionary Loughran and McDonald (2014), based on the sample of companies with a developed market and the sample of Russian news.

Table 1 illustrates the formulas that reflect the emotional characteristic of the text of the call transcript (linguistic variables) in accordance with the NRC dictionary.

To test the hypotheses $1-3$, the regression models will be built based on panel data applying conference call transcripts where the semantic and linguistic characteristics are the explanatory variables, and future market and financial indicators of the company, as well as analysts' recommendations regarding the attractiveness of the stock, are dependent variables.

Additionally, the control variables are included in regression models that are estimated below. It is necessary, firstly, to fix the effect of non-financial information on the company's future market performance and its tonality level, and secondly, these factors have been successfully tested and applied in recent empirical studies in this field (Davis et al., 2006, 2012; Demers and Vega, 2008; Price et al., 2012; Boudt and Thewissen, 2019; Fyodorova et al., 2017, Demin et al., 2019), where these variables improved the general explanatory power and significance of the regression model.

The financial (control) variables are used with a lag of 1 year in the presented models below (the control variables for the fiscal year 2018 are used for the call of 2019). Since the call is conducted on the basis of financial and operational results from the previous year, the model output considers the linguistic textual factors

Table 1

Description of linguistic variables.

\begin{tabular}{|c|c|c|}
\hline Variable & Formula & Definition \\
\hline PosSent $t_{t}$ & $\frac{\text { PosWords }_{t}}{\text { TotWords }_{t}}$ & $\begin{array}{l}\text { Text positivism in conference call } \\
\text { PosWords }_{t} \text { - number of positive words in conf. call } \\
\text { TotWords }_{t} \text { - total number of words in conf. call }\end{array}$ \\
\hline NegSent $_{t}$ & $\frac{\text { NegWords }_{t}}{\text { TotWords }_{t}}$ & $\begin{array}{l}\text { Text negativism in conference call } \\
\text { NegWords } s_{t} \text { - number of negative words in conf. call } \\
\text { TotWords }_{t} \text { - total number of words in conf. call }\end{array}$ \\
\hline NetSent $t_{t}$ & $\frac{\text { PosWords }_{t}-\text { NegWords }_{t}}{\text { PosWord }_{t}+\text { NegWords }_{t}}$ & $\begin{array}{l}\text { The general direction of the conference call tone } \\
\text { (Net sentiment) }\end{array}$ \\
\hline EnvirSent $_{t}$ & $\frac{\text { EnvirWords }_{t}}{\text { TotWords }_{t}}$ & $\begin{array}{l}\text { EnvirWords } s_{t} \text { - number words of "ecology" topic } \\
\text { TotWords } s_{t} \text { - total number of words in conf. call }\end{array}$ \\
\hline SocialSent $_{t}$ & $\frac{\text { SocialWords }_{t}}{\text { TotWords }_{t}}$ & $\begin{array}{l}\text { SocialWord } s_{t} \text { - number words of "corporate social" } \\
\text { thematic in conference call } \\
\text { TotWords } s_{t} \text { - total number of words in conf. call }\end{array}$ \\
\hline
\end{tabular}

Source: Compiled by the authors. 
separately from the impact of financials. Control variables are used to separate the "financial impact" of information on future share return from the effects of "linguistic" and "thematic" influence.

The main control variables used are ROE, ROA, Size (logarithm of revenue / assets), Asset Turnover, Leverage, financial covenant Net Debt/EBITDA, logarithm of working capital change in this study (Change in $W C_{i, t+1}$ ).

To test hypothesis 1 , a regression model (1) was constructed which is presented below:

$$
\begin{aligned}
C A R(0, T)_{i, t} & =\beta_{0}+\beta_{1} \times \operatorname{ROE}_{i, t-1}+\beta_{2} \times \text { Size }_{i, t-1}+\beta_{3} \times A T_{i, t-1}+ \\
& +\beta_{4} \times \text { EBITDA }_{\text {Margin }_{i, t-1}}+\beta_{5} \times \text { NetSent }_{i, t-1}+ \\
& +\beta_{6} \times \text { Change in } W C_{i, t-1}+\varepsilon_{i, t},
\end{aligned}
$$

where:

$C A R(0, T)_{i, t}=\sum_{\tau=0}^{T} A R_{\tau}$ - cumulative abnormal return since $T$ days after conf. call of company $i$ for year $t$;

$A R_{\tau}$ - abnormal return in day $\tau$ of company $i$ for year $t$;

$A R_{\tau}=\operatorname{Ln} \frac{P_{i, \tau}}{P_{i, \tau-1}}-\operatorname{Ln} \frac{P_{m, \tau}}{P_{m, \tau-1}}$

$P_{i, \tau}$ - share price of company $i$ in day $\tau$;

$P_{m, \tau}-$ market index $m$ in day $\tau$.

In this study, the market value (return) of the stock exchange index is measured as the component of excess returns $(A R)$ instead of the classically applied expected return $E R_{i, \tau}$ in financial theory. Firstly, this is explained by using $P_{m, \tau}$ instead of $E R_{i, \tau}$ in most modern works in the field of finance, and, secondly, the application of $E R_{i, \tau}$ is possible only together with the assumption of the perfect financial market and with a number of the assumptions of CAPM model, which can be broken in real financial markets. The Moscow Stock Exchange Index was used as a market index for the Moscow Stock Exchange companies and the FTSE100 index for companies from the London Stock Exchange.

Various modifications of the parameter will be used depending on the number of days ( $T$ ) after the conference call (3 days / 14 days / 30 days) since hypothesis 1 is tested on the short and medium term.

To test hypothesis 2, model (1) will be modified as follows:

$$
\begin{gathered}
\Delta \operatorname{Recomm}(0, T)_{i, t}=\beta_{0}+\beta_{1} \times \operatorname{ROE}_{i, t-1}+\beta_{2} \times \operatorname{Size}_{i, t-1}+\beta_{3} \times A T_{i, t-1}+ \\
+\beta_{4} \times{\text { EBITDA } \text { Margin }_{i, t-1}+\beta_{5} \times \text { NegSent_Q\& } \& A_{i, t-1}+}^{+} \\
+\beta_{6} \times \text { Change in } W C_{i, t-1}+\varepsilon_{i, t-1},
\end{gathered}
$$

where $\Delta \operatorname{Recomm}(0, T)_{i, t}=\operatorname{Recomm}(T)_{i, t}-\operatorname{Recomm}(0)_{i, t-1}-$ change in mean analysts recomendation for period $[0 ; T]$.

In model (2), the following classification is considered as a recommendation for a specific stock that is proposed by Thomson Reuters and Bloomberg: 1 - strictly buy, 2-buy, 3-neutral (hold), 4-sell, 5-strictly sell. Thus, if 
the variable $\Delta \operatorname{Recomm}(0, T)_{i, t+1}$ is negative, the recommendation for the (equity) share improves in a favorable way for the purchase. In the model, this variable will be applied in two versions: a short-term change (1 month) and long-term change in the recommendation (till the end of the year since the conference call ending).

To test hypothesis 3, we also modify model (1) in part of the parameter PosSent $_{i, t}$ (reflects the tone of the complete text), instead of which we apply separately PosSentManagement ${ }_{i, t}$ and PosSentAnalyst $t_{i, t}$. The hypothesis will be verified by comparing the estimates of the coefficients $\beta_{i}$ for these variables by module.

To test hypothesis 4, the regression model (3) is constructed based on panel data and presented below, which is the modification of the model (1), where the variable PosSent $t_{i, t}$ is excluded (because it directly correlates with the variable $\left.\operatorname{Words}_{i, t}\right)$ :

$$
\begin{aligned}
& \operatorname{CAR}(0,3)_{i, t}=\beta_{0}+\beta_{1} \times R O E_{i, t-1}+\beta_{2} \times \operatorname{Size}_{i, t-1}+\beta_{3} \times A T_{i, t-1}+ \\
& +\beta_{4} \times \text { EBITDA }_{\text {Margin }_{i, t-1}}+\beta_{5} \times \text { Words }_{i, t-1}+ \\
& +\beta_{6} \times F O G_{i, t-1}+\beta_{7} \times \text { Change in } W C_{i, t-1}+\varepsilon_{i, t} \text {, }
\end{aligned}
$$

where: $\operatorname{Words}_{i, t}$ — number of total words in a conference call;

$F O G_{i, t}$ - coefficient of the complexity of text understanding (Li, 2008):

$F O G_{i, t}=0.4 \times\left(\frac{\text { Total Words }}{\text { Number of Sentences }}+\frac{\text { Number of complicated words }}{\text { Total Words }} \times 100\right)$.

Table 2 illustrates the relation between the value of the FOG index and the degree of complexity and readability of the analyzed text. As a dependent variable, the different modifications of the variable $\operatorname{CAR}(0, T)_{i, t}$ will be proposed in order to measure the significance of the effect in the short and medium term (up to 1 month).

The particular method of research in the context of text analysis is the estimation of the significance of non-financial information and its impact on the company's future performance and the accuracy of analysts' forecasts regarding key performance indicators (earnings per share, dividend surprise). Linguists and economists have done massive research to create and compile thematic dictionaries in 2010-2018 based on various materials and scientific sources that allow to cluster words and spoken phrases in specific topics. Among the modern and most authoritative dictionaries in the scientific community, it seems possible to highlight the Corporate Social Responsibility Words dictionary (Pencle and Mălăescu, 2016) that corresponds to

Table 2

FOG Index distribution (level of text complexity).

\begin{tabular}{ll}
\hline FOG Index & Text characteristic \\
\hline$\geq 18$ & Impossible to read \\
$14-17.99$ & Difficult to read \\
$12-13.99$ & Text is completely clear \\
$10-11.99$ & Acceptable for reading \\
$8-9.99$ & Simple text \\
\hline
\end{tabular}

Source: Authors' calculations. 
the topic of corporate social responsibility. The dictionary let the researchers cluster the existing text in four ways: social responsibility and social activities, environment and ecology, protection of human rights, motivation and support of workers. Each of the four dictionary clusters has more than 1 thousand words in the lexicon; the following most popular can be distinguished among them: "Collective Well-Being", "Corporate Culture", "Discrimination", "Diverse", "Healthcare Benefits", "Hard Work", "Carbon Emission", "Environment", "Petroleum", "Renewable", "Life Benefits", "Social Policy".

To test hypotheses $5 \mathrm{a}$ and $5 \mathrm{~b}$ on the basis of the analyzed literature, the variables responsible for the thematic focus of the call transcript will be included to the modification of model (1):

$$
\begin{aligned}
{\operatorname{CAR}(0,3)_{i, t}} & \beta_{0}+\beta_{1} \times \text { ROE }_{i, t-1}+\beta_{2} \times \text { Size }_{i, t-1}+\beta_{3} \times A T_{i, t-1}+ \\
& +\beta_{4} \times{\text { EBITDA } \text { Margin }_{i, t-1}+\beta_{5} \times \text { Social }_{i, t-1}+}+ \\
& +\beta_{6} \times \text { Envir }_{i, t-1}+\beta_{7} \times \text { Humanr }_{i, t-1}+\varepsilon_{i, t}, \\
\text { EPS_Surp }_{i, t} & =\text { ROE }_{i, t-1}+\text { Size }_{i, t-1}+\text { AT }_{i, t-1}+ \\
& + \text { EBITDAMargin }_{i, t-1}+\text { Social }_{i, t-1}+ \\
& + \text { Envir }_{i, t-1}+\beta_{7} \times \text { Humanr }_{i, t-1}+\varepsilon_{i, t},
\end{aligned}
$$

where: Social $_{i, t}$ — share of words about corporate social thematic in call; Envir ${ }_{i, t}$ share of words about environmental thematic; Humanr ${ }_{i, t}$ - share of words about human and worker rights; EPS_Surp ${ }_{i, t 1}=E P S$ fact $_{i, t}-$ EPS $_{\text {forecast }_{i, t-1}}$ - analyst forecast error of earnings per share ("earnings per share surprise").

Previously, these hypotheses were not tested by researchers, since there were no specialized thematic dictionaries and tools for testing them.

To verify hypothesis 6 , the model (1) itself was tested separately for a selection of conference calls for management of companies in Moscow and London Stock Exchanges in order to find significant difference in estimates of coefficients for linguistic variables.

\section{Sample selection: data analysis and criteria}

To test the advanced hypotheses and in accordance with the research branch, further companies were selected from different financial markets based on the following selection criteria: companies are public and have been trading on the Moscow and London Stock Exchanges continuously since 2014 and are in the top 100 of the market capitalization and the top 100 of daily trading volume among firms on the exchanges; availability of annual conference calls' transcripts with investors and analysts without omissions in English in 2015-2019; the minimum number of words in the text of the call exceeds 200 words; the absence of gaps in historical financial results and variables in the Thomson Reuters and Bloomberg databases that are used in the research.

The initial sample of companies in the study consisted of 75 companies from the London Stock Exchange and 60 companies from the Moscow Stock Exchange, but, in the process of financial information and conference call transcripts' 
consolidation, the observations (companies) were excluded where several transcripts were missing or there were significant omissions ( $>5 \%$ observations of all data) by historical data. The final sample consists of 36 companies in MOEX and 35 companies of the LSE, where the equity of these companies have been traded continuously since 2015 .

Tables 3-4 provide the descriptive analysis of the financial performance of companies for 2015-2019 separately for the Moscow and London exchanges. The descriptive analysis illustrates that Russian and European companies are comparable in terms of assets and revenue level with a slight advantage of companies from the London Stock Exchange, but other characteristics differ between companies of these regions with a greater dispersion of the variables among Russian firms. Despite this difference, the "dividend surprise" and "earnings per share surprise" are almost the same between the represented companies, but at the same time, Russian market analysts are more inclined to increase the recommendation of equity ("buy") than their European colleagues - the average recommendation after conference calls is in favor of decline ("sell"); that can be justified by the lack of sufficient information from the management of Russian

Table 3

Descriptive analysis of financial variables (MOEX companies).

\begin{tabular}{lcccccc}
\hline Variable & Min & $\mathrm{Q}_{1}$ & Median & Mean & $\mathrm{Q}_{3}$ & Max \\
\hline Market Cap & 8.65 & 9.51 & 9.82 & 9.84 & 10.14 & 10.91 \\
Size (Log Assets) & 8.67 & 9.71 & 9.96 & 10.06 & 10.23 & 11.67 \\
ROE, \% & -87.0 & 10.0 & 18.0 & 23.0 & 28.0 & 459.0 \\
EBITDA_margin, \% & 5.0 & 15.0 & 26.0 & 28.0 & 34.0 & 80.0 \\
Net Debt/EBITDA & 0.0 & 0.73 & 1.39 & 3.09 & 2.14 & 91.33 \\
Leverage & 0.0 & 0.36 & 1.10 & 3.10 & 2.41 & 52.91 \\
Asset Turnover & 0.00 & 0.51 & 0.67 & 0.81 & 0.96 & 2.51 \\
Change in WC & -10.34 & -8.72 & -8.46 & -5.21 & -7.74 & 10.21 \\
EPS_Surprise, \% & -25.0 & -1.0 & 0.0 & 1.0 & 3.0 & 27.0 \\
Recommendation & -1.50 & -0.06 & 0.00 & -0.02 & 0.01 & 1.80 \\
CAR $(0,3)$ & -0.15 & -0.06 & -0.02 & 0.01 & 0.06 & 0.34 \\
CAR (0,14) & -0.36 & -0.10 & -0.01 & 0.02 & 0.07 & 0.94 \\
CAR (0,30) & -1.17 & -0.04 & 0.01 & 0.04 & 0.09 & 1.51 \\
\hline
\end{tabular}

Source: Authors' calculations.

Table 4

Descriptive analysis of financial variables (LSE companies).

\begin{tabular}{lcccccc}
\hline Variable & Min & $\mathrm{Q}_{1}$ & Median & Mean & $\mathrm{Q}_{3}$ & Max \\
\hline Market Cap & 9.55 & 9.85 & 10.29 & 10.32 & 10.74 & 11.24 \\
Size (Log Assets) & 9.13 & 9.85 & 10.45 & 10.48 & 10.96 & 12.42 \\
ROE, \% & -5.0 & 9.0 & 14.0 & 16.0 & 22.0 & 57.0 \\
EBITDA_margin, \% & -0.06 & 0.14 & 0.28 & 0.34 & 0.42 & 1.80 \\
Net Debt/EBITDA & 0.00 & 0.62 & 1.23 & 2.25 & 2.25 & 38.13 \\
Leverage & 0.08 & 0.45 & 0.68 & 1.21 & 1.55 & 10.98 \\
Asset Turnover & 0.00 & 0.24 & 0.46 & 0.56 & 0.85 & 1.66 \\
Change in WC & -10.83 & -9.07 & -8.25 & -4.22 & 6.93 & 10.74 \\
EPS_Surprise, \% & -170.0 & -1.0 & 0.0 & -1.0 & 1.0 & 48.0 \\
Recommendation & -0.89 & -0.12 & 0.00 & 0.01 & 0.09 & 3.00 \\
CAR $(0,3)$ & -0.15 & -0.02 & 0.01 & 0.01 & 0.04 & 0.27 \\
CAR $(0,14)$ & -0.11 & -0.01 & 0.03 & 0.03 & 0.06 & 0.45 \\
CAR $(0,30)$ & -0.16 & -0.04 & 0.01 & 0.02 & 0.07 & 0.69 \\
\hline
\end{tabular}

Source: Authors' calculations. 
companies. In addition, it can be seen that the stock reaction ("excess return") between the markets is almost comparable with a small difference in the pessimistic reaction of the Russian market in the 3-day interval after the call.

On the other hand, attention should mostly be paid to descriptive statistics of linguistic variables of the conference calls (Tables 5-6): the text features of conference calls between the years significantly differ since the interest in this type of communication among management and market analysts increases every year; the number of words in the call of European companies is almost twice that of Russian calls, which is explained by the earlier start of using conference calls to disclose information in Europe. However, the FOG text complexity index illustrates that call texts for Russian companies are more comprehensive and less primitive, despite lesser volume of words. It can be noted that both positivism of the call tone (PosSent) and general tone (NetSent) practically do not differ between the samples with a slight advantage of positivity for companies in the Russian financial market.

Thematic coverage of environmental aspects of the call with analysts ("Environment") is practically the same, despite the fact that government regula-

Table 5

Descriptive analysis of linguistic and thematic variables (MOEX companies).

\begin{tabular}{|c|c|c|c|c|c|c|}
\hline Variable & Min & $\mathrm{Q}_{1}$ & Median & Mean & $\mathrm{Q}_{3}$ & Max \\
\hline Words & 689 & 2460 & 3473 & 3549 & 4266 & 12939 \\
\hline FOG Index & 10.56 & 12.26 & 12.94 & 13.02 & 13.57 & 17.79 \\
\hline PosSent & 0.09 & 0.11 & 0.12 & 0.12 & 0.13 & 0.17 \\
\hline NegSent & 0.02 & 0.03 & 0.03 & 0.03 & 0.04 & 0.08 \\
\hline NetSent & 0.03 & 0.07 & 0.08 & 0.09 & 0.09 & 0.15 \\
\hline Environment & 0.01 & 0.02 & 0.02 & 0.02 & 0.03 & 0.05 \\
\hline Social Disclosure & 0.01 & 0.02 & 0.02 & 0.02 & 0.02 & 0.04 \\
\hline Human Rights & 0.00 & 0.01 & 0.01 & 0.01 & 0.01 & 0.03 \\
\hline Words_Q\&A & 68 & 1171 & 1814 & 1917 & 2376 & 6364 \\
\hline FOG Index_Q\&A & 10.04 & 12.07 & 12.78 & 12.84 & 13.52 & 19.26 \\
\hline PosSent_Q\&A & 0.06 & 0.11 & 0.12 & 0.12 & 0.13 & 0.18 \\
\hline NegSent_Q\&A & 0.00 & 0.02 & 0.03 & 0.03 & 0.04 & 0.09 \\
\hline NetSent_Q\&A & 0.02 & 0.07 & 0.09 & 0.09 & 0.10 & 0.15 \\
\hline
\end{tabular}

Source: Authors' calculations.

Table 6

Descriptive analysis of linguistic and thematic variables (LSE companies).

\begin{tabular}{|c|c|c|c|c|c|c|}
\hline Variable & Min & $\mathrm{Q}_{1}$ & Median & Mean & $\mathrm{Q}_{3}$ & Max \\
\hline Words & 1556 & 4764 & 6009 & 6154 & 7466 & 13317 \\
\hline FOG Index & 9.45 & 11.56 & 12.37 & 12.35 & 13.03 & 16.26 \\
\hline PosSent & 0.08 & 0.11 & 0.11 & 0.11 & 0.12 & 0.15 \\
\hline NegSent & 0.02 & 0.03 & 0.03 & 0.03 & 0.04 & 0.05 \\
\hline NetSent & 0.04 & 0.07 & 0.08 & 0.08 & 0.09 & 0.13 \\
\hline Environment & 0.01 & 0.02 & 0.02 & 0.03 & 0.03 & 0.05 \\
\hline Social Disclosure & 0.01 & 0.02 & 0.03 & 0.03 & 0.03 & 0.06 \\
\hline Human Rights & 0.01 & 0.01 & 0.02 & 0.02 & 0.02 & 0.04 \\
\hline Words_Q\&A & 317 & 2297 & 3279 & 3219 & 4032 & 8302 \\
\hline FOG Index_Q\&A & 9.38 & 11.02 & 11.75 & 11.77 & 12.32 & 21.14 \\
\hline PosSent_Q\&A & 0.07 & 0.09 & 0.10 & 0.10 & 0.11 & 0.14 \\
\hline NegSent_Q\&A & 0.01 & 0.02 & 0.03 & 0.03 & 0.03 & 0.05 \\
\hline NetSent_Q\&A & 0.05 & 0.07 & 0.07 & 0.07 & 0.10 & 0.12 \\
\hline
\end{tabular}

Source: Authors' calculations. 
tion and the emphasis on green production is much stronger in Europe. In contrast, there is an advantage in disclosing the topics of social responsibility and protecting human rights among the companies of the London Exchange, which is supported by facts (the requirement of society and the EU for the mandatory disclosure and coverage of this information). At the same time, for both samples, the total word volume in the question-answer part (Q\&A) of the call is almost 2 times lower than the conference call as a whole with more primitiveness and simplicity of proposals for companies of the London Stock Exchange. That may indicate an attempt to manipulate the topics by the management of Russian corporations when in the Q\&A part (“difficult readability"). The emotional color (PosSent, NetSent) of the Q\&A part of the call is brighter for Russian companies, which is manifested in the volume of positive and negative tone. It can be explained by their relative inexperience in conducting such events, both on the side of company management and market analysts in comparison to companies on the London Stock Exchange, that use a more restrained tone in the call.

Fig. 2 presents the most popular words for the general sample of conference calls by topics: social and environmental responsibility. As can be seen from

(a) Most popular positive words

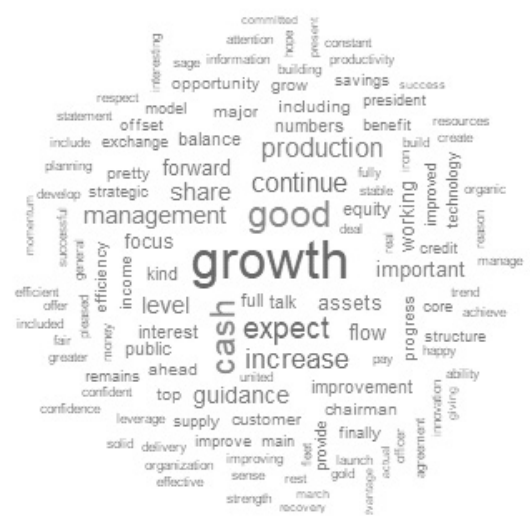

(c) Most popular words of corporate social thematics

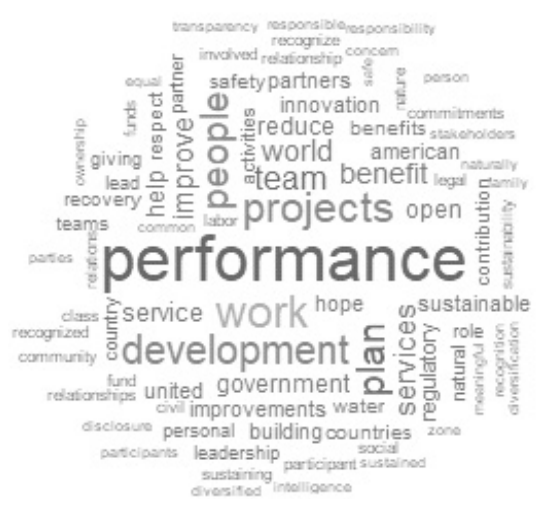

(b) Most popular negative words

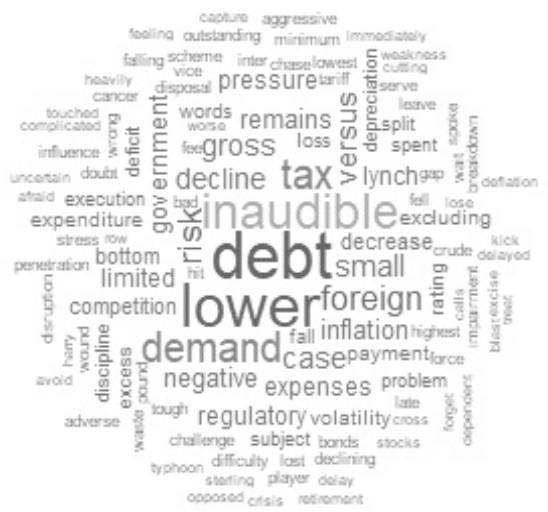

(d) Most popular words in "ecology"

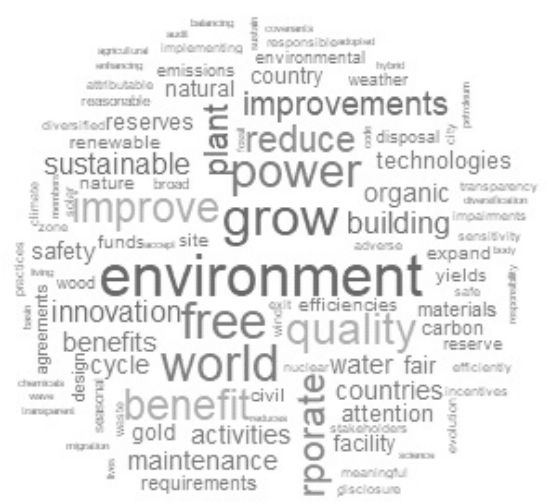

Fig. 2. Most popular words for the general sample of conference calls by topics: social and environmental responsibility.

Source: Compiled by the authors. 
(a) MOEX

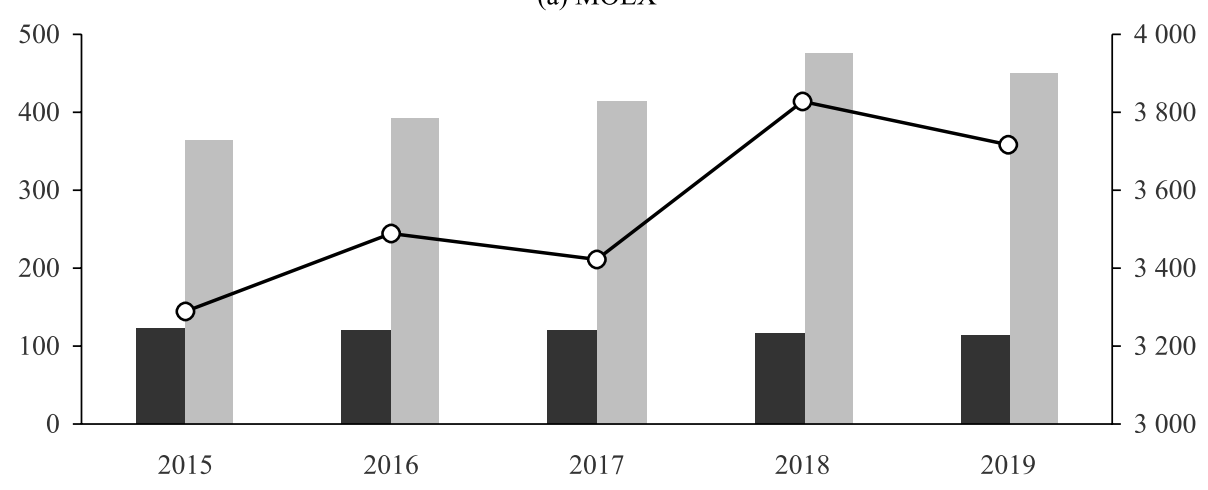

(b) LSE

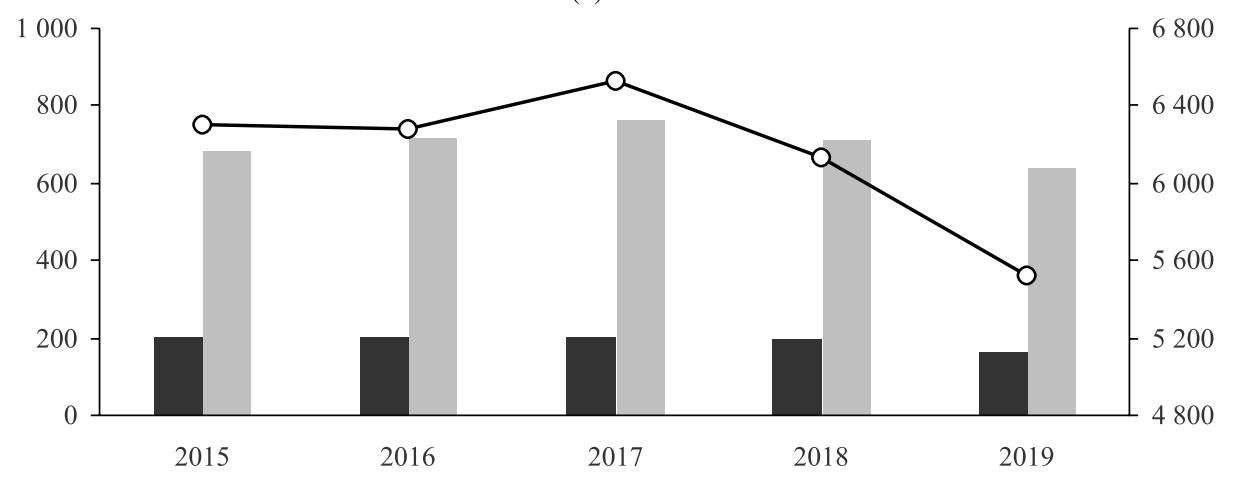

Negative words Positive words $-0-$ Total number of words (right-hand scale)

Fig. 3. Dynamics of positive and negative words in conference calls for 2015-2019, MOEX and LSE companies.

Source: Authors' calculations.

Fig. 2, the most popular positive words in the call with analysts and investors were the words: "growth", "good", "increase", "cash", and negative_—“debt", "risk", "demand" , "tax", "decline'. At the same time, in social thematics, the words "performance", "projects", "people", "development" were used to a greater degree, and in the direction of ecology topic_- "environment", "power", "reduce", "quality" and "plant".

Fig. 3 shows the dynamics of the duration and tonality of conference calls by year: there has been a tendency over the past five years to increase the number of words in calls with analysts for Russian companies with the growth in the positive focus of the text and a constant level of using negative words, which led to an increase in the overall positive tonality and emotional coloring of the call. However, this dynamic is opposite for European companies: the decrease in the average number of words in the calls by $10-15 \%$ with a similar decrease in the volume of positive and negative words, and thus the overall emotional coloring of the call has not changed much over the past 5 years.

Fig. 4 illustrates the dynamics of the thematic focus in the call with investors and market analysts: there is a noticeable tendency for words to grow in each of 
(a) MOEX

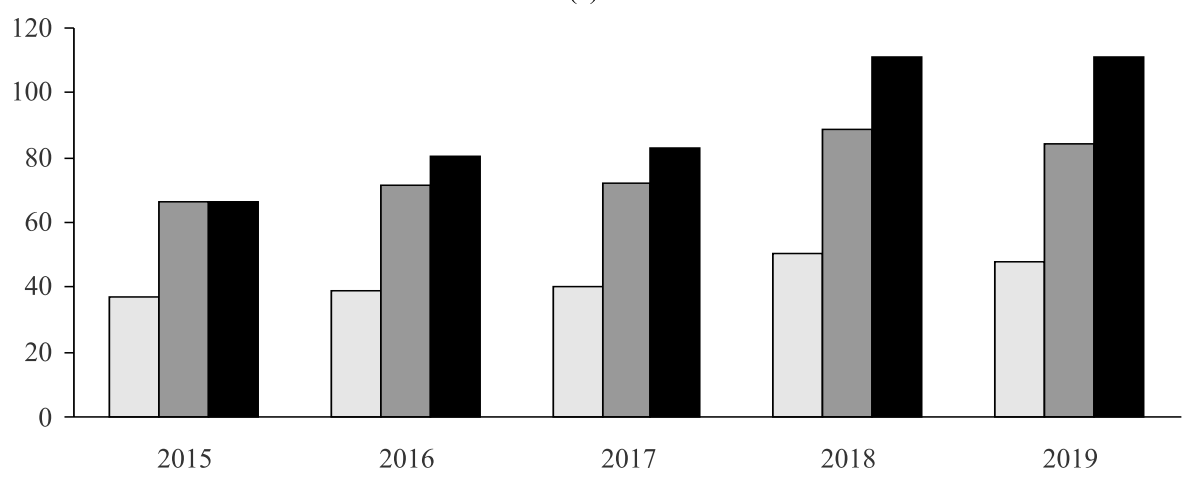

(b) LSE

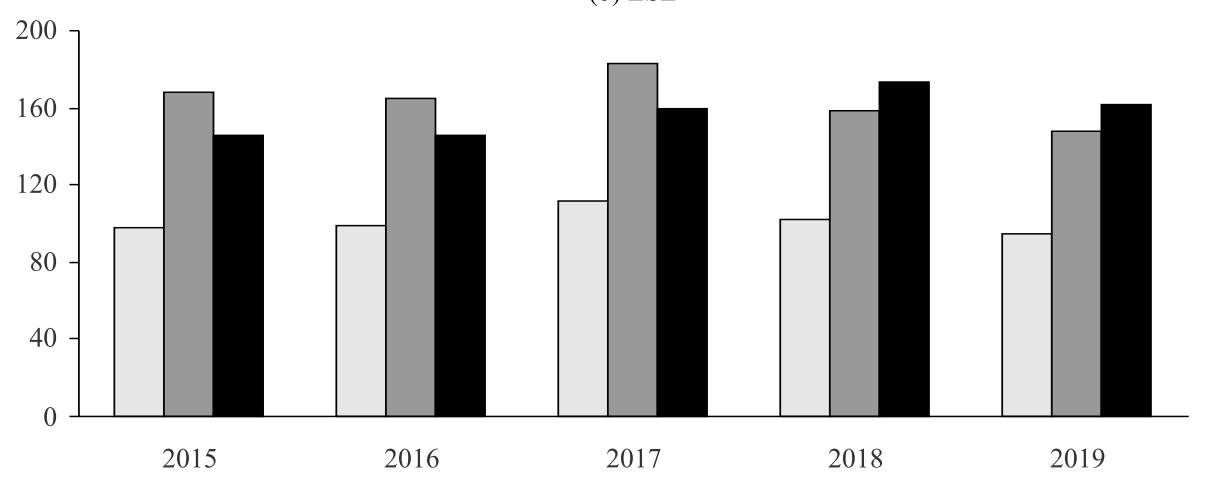

Human rights $\square$ Social responsibility responsibility $\square$ Ecology

Fig. 4. Dynamics of thematic words in conference calls for 2015-2019, MOEX and LSE companies.

Source: Authors' calculations.

all the thematics for Russian companies until 2018-environmental and social responsibility, protecting human rights - with a slight decrease of using these words in 2019. The general word trend for companies of the LSE is multidirectional: the decrease in thematic coverage of social orientation and protection of human rights, which are explained by a decrease in the total volume of words in a call, but at the same time there is a significant increase in words in the subject of "ecology and environment", which can be interpreted by tightening policies in this sphere by the state and institutional pressure.

The greater volume (number) of words in the topics of protecting human rights, social responsibility and the environment for LSE companies is explained, on the one hand, by the mandatory disclosure of this thematic in the EU region since 2012, and, on the other hand, by a large number of words in the framework of the conference call.

The complexity and the difficult readability of the text of the call has increased over the past five years for companies of both stock exchanges; however, the text of the Russian companies' call is more comprehensive. Variable Net Sentiment (general call tone) also increased for companies in both samples, however, 
the calls of MOEX companies are more positive in 2019, despite almost the same tone level in 2015, which may indicate that Russian management is currently trying to semantically manipulate and distort the disclosed information.

\section{Empirical results}

The results of the study and the testing of hypotheses 1-3 (for the event window of 14 calendar days after the call) are depicted in Table 7.

The study illustrates that the emotional coloring of the call (general tone), and the length and complexity of the text are significant factors that determine the future excess return of equities of companies from both stock exchanges (Moscow and London). This result is consistent with most studies of the past few years in developed capital markets. Hypothesis 1 about the significance of the general tone of the conference call text was confirmed in Price et al., 2012; Brockman et al., 2017, in samples of companies from developed markets, but did not find verification in Fyodorova et al., 2017, in a sample of CEO Letters of Russian companies. The results allow to conclude that non-fundamental factors (topmanagement tone and depth of disclosed information in the call) can be used by public company management to increase the market value of companies' equities in comparison with the market index in the short term after the call completion (up to 30 days).

However, the analyst's tone in the call is not significantly connected with subsequent valuation (recommendation) of the company equity because of the probable presence of more significant variables (financial results) that affect analyst recommendations. In addition, the insignificant results of testing this hypothesis can be explained by the short-term horizon of the calculation of the variable "change in share recommendation" (up to 1 month), since many analysts might not yet update the recommendation taking into account the information received about the company in the call. It can be noticed that earlier this hypothesis was not tested by researchers, despite the availability of the data of average and median estimates of analysts' recommendations in shares of public companies.

Moreover, the hypothesis of a stronger influence of the analyst's tone than that of the management on future stock returns was confirmed only for companies of LSE. This result can be explained by the greater importance in the Russian stock market of the tone and topics of company management than market analysts, who are mainly only the link between corporations and the market. Besides, in previous works, the authors also received mixed results: this assumption was rejected in Price et al. (2012), however, the opposite conclusion was provided in Boudt and Thewissen (2019). The results of testing the hypotheses 4-5 are presented in Table 8 (for a window of 14 calendar days after the call).

The complexity, readability and the length of the call text and top management Letters are the most popular hypotheses that are advanced and tested by the authors in this field. In this study, hypothesis 4 on the significance of the length and complexity of the text is not rejected, which confirms the results of recent studies (Loughran and McDonald, 2014; Brockman et al., 2017; Borochin et al., 2018; Li, 2006, 2008), however, according to the sample of CEO Letters of Russian companies, Fyodorova et al. (2017) concluded the insignificance of these factors in the link to the financial performance of public wfirms. In 


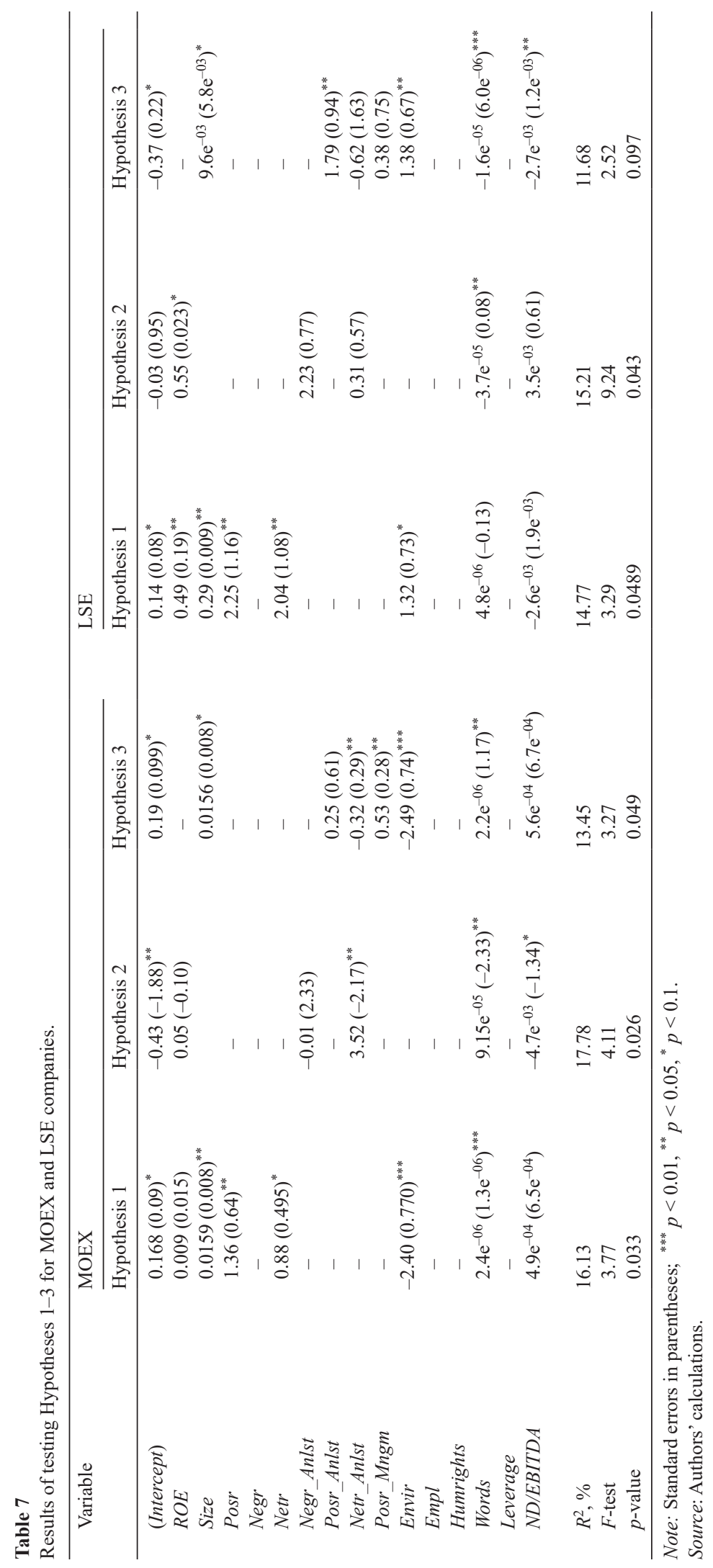




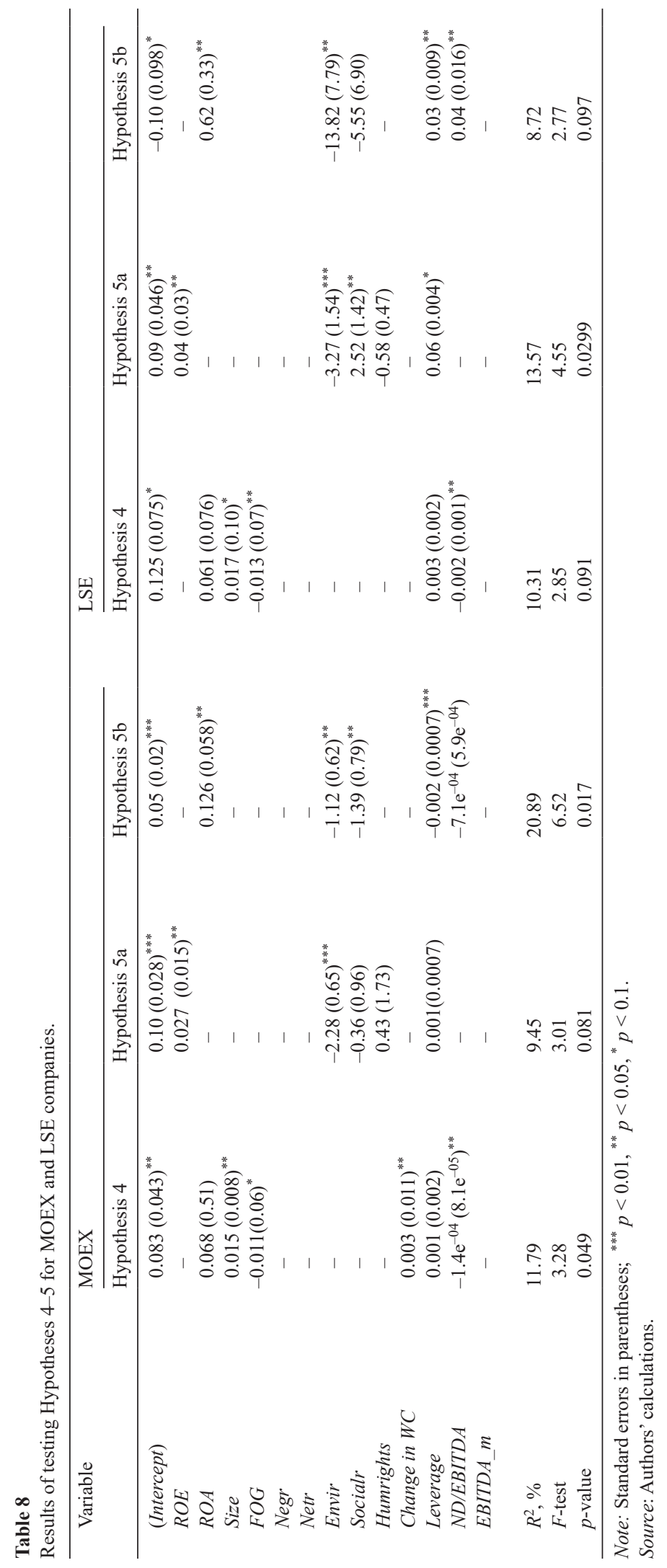


addition, testing hypotheses $5 \mathrm{a}$ and $5 \mathrm{~b}$ revealed that a certain topic and agenda (ecology and social responsibility) have a significant impact on excess stock returns (CAR), but only the conference calls' topic of MOEX companies affect the forecast error of EPS by analysts. The obtained results may indicate that all disclosed information (non-financial information is mandatory for disclosure in the EU countries, for example, ESG reports) in European companies is already taken into account in the forecast of analysts, but the absence of such information for many Russian companies makes social and environmental topics in the call of company management significant and affecting subsequent market performance.

Moreover, the disclosure of environmental topics is more likely associated with a discussion of its negative aspects and demonstrations-emissions, environmental accidents, and high investment costs to reduce pollution that ultimately negatively affects the market share price of equities after the call execution. Previously, these hypotheses were not tested by researchers, since there were no specialized thematic dictionaries and the tools for testing them.

The application of machine learning, namely the neural network of the MLP type (multilayer perceptron), as an alternative test of the advanced hypotheses, illustrates that the linguistic variables included in the model reduce the network error by $4-17 \%$ on the average and increase the correlation between the predicted and the actual value of the dependent variable by 5-13\% (Appendix A). The Appendix B illustrates the example of MLP neural network simulation for testing the hypothesis $5 \mathrm{~b}$.

\section{Conclusion}

The results of the regression analysis and the neural network estimation in the framework of hypothesis testing illustrate the fact that the semantic and thematic characteristics of annual conference calls of management with investors and analysts affect significantly the future market performance of the company and the forecast error earnings per share by analysts in the short and mediumterm intervals ( 3 days/14 days/30 days). However, there is no significant relation between these indicators and analysts' recommendations per share a month after the conference call. At the same time, it should be noted that the financial market affects the direction and importance of text information used by management, which ultimately affects the results of the influence of text characteristics and features of conference calls on the future market performance of public companies. In addition, a significant regional difference in the tone and manipulation of semantic and thematic characteristics of calls is revealed for companies from the Moscow and London Stock Exchanges.

The empirical significance of the research is in the opportunity of subsequent application of its results by the management of public companies for correct management and control of tone, topics and depth of information disclosure in the framework of the conference call. It is important in order to form and improve its attractiveness and the image for investors and market analysts, to increase the market value of the company due to the growth of stock quotes and improving the recommendations of analysts regarding its attractiveness in the short and long term. 
The application of the results in this article is possible in two ways: firstly, by management of public companies from developed and emerging markets to reduce the negative perception of financial results and strategies discussed by analysts and investors, reducing the overall level of panic and behavioral irrationality in the short term; and secondly, by investors and analysts to more accurately predict the future financial, operational performance of the company, the strategy being implemented and identify excessive optimism or pessimism of management, which can be reflected in price dynamics both in the short and long term.

\section{References}

Bannier, C., Pauls, T., \& Walter, A. (2017). The BPW: Introducing a German dictionary for computer aided quantitative content analyses. Unpublished manuscript.

Borochin, P. A., Cicon, J. E., DeLisle, R. \& Price, S. M. (2018). The effects of conference call tones on market perceptions of value uncertainty. Journal of Financial Markets, 40. https://doi. org/10.1016/j.finmar.2017.12.003

Boudt, K., \& Thewissen, J. (2019). Jockeying for position in CEO Letters: Impression management and sentiment analytics. Financial Management, 48 (1), 77-115. https://doi.org/10.1111/ fima.12219

Brockman, P., Li, X., \& Price, S. M. (2015). Differences in conference call tones: Managers versus analysts. Financial Analysts Journal, 71 (4), 24-42. http://dx.doi.org/10.2139/ssrn.2543993

Brockman, P., Li, X., \& Price, S. M. (2017). Conference call tone and stock returns: Evidence from the Stock Exchange of Hong Kong. Asia Pacific Journal of Financial Studies, 46, 667-685.

Courtis, J. K. (1998). Annual report readability variability: Tests of the obfuscation hypothesis. Accounting, Auditing and Accountability Journal, 11 (4), 459-471. https://doi. org/10.1108/09513579810231457

Courtis, J. K. (2004). Corporate report obfuscation: Artefact or phenomenon? British Accounting Review, 36 (3), 291-312. https://doi.org/10.1016/j.bar.2004.03.005

Craig, R., \& Brennan, N. (2012). An exploration of the relationship between language choice in CEO letters to shareholders and corporate reputation. Accounting Forum, 36 (3), 166-177

Davis, A., Piger, J., \& Sedor, L. (2006). Beyond the numbers: Managers' use of optimistic and pessimistic tone in earnings press releases. Working Paper No. 2006-005, Federal Reserve Bank of St. Louis. https://doi.org/10.20955/wp.2006.005

Davis, A. K., Piger, J. M., \& Sedor, L. M. (2012). Beyond the numbers: Measuring the information content of earnings press release language. Contemporary Accounting Research, 29 (3), 845-868. https://doi.org/10.1111/j.1911-3846.2011.01130.x

Demers, E., \& Vega, C. (2008). Soft information in earnings announcements: News or noise? INSEAD Working Paper, Fontainebleau, France.

Demin, I., Fyodorova, E., \& Rogov, O. (2019). Applications of the sentiment polarity dictionaries for the textual analysis. Journal of Applied Informatics, 14 (1), 5-16 (in Russian).

Doran, J., Peterson, D., \& Price, S. M. (2012). Earnings conference call content and stock price: The case of REITs. Journal of Real Estate Finance and Economics, 45 (2), 402-434. https:// doi.org/10.1007/s11146-010-9266-z

Fyodorova, E., Demin, I., Khrustova, L., Osetrov, R., \& Fedorov, F. (2017). The influence of CEO letters' tone on financial indicators of the company. Russian Management Journal, 15 (4), 441462 (in Russian). https://doi.org/10.21638/11701/spbu18.2017.403

Fyodorova, E., Ledyaeva, S., Fedorov, F., Demin, I., \& Denisova, T. (2019). Influence of CEOs optimism and narcissism on the company's capital structure. Journal of Corporate Finance Research, 13 (1), 60-75. https://doi.org/10.17323/j.jcfr.2073-0438.13.1.2019.60-75

Fung, G., Yu, J., Yu, X., \& Lam, W. (2002). News sensitive stock trend prediction. Pacific-Asia Conference on Knowledge Discovery and Data Mining (PAKDD), Taipei, Taiwan.

Jegadeesh, N., Kim, J., Krische, S. D., \& Lee, C. M. C. (2004). Analyzing the analysts: When do recommendations add value? Journal of Finance, 59 (3), 1083-1124. https://doi.org/10.1111/ j.1540-6261.2004.00657.x 
Kelchevskaya, N., Chernenko, I., \& Popova, E. (2017). The impact of corporate social responsibility on the investment attractiveness of the Russian companies. Economy of Region, 13 (1), 157-169 (in Russian). https://doi.org/10.17059/2017-1-15

Kontio, C. (2016). Do analysts know it better? Sell-side analyst recommendations and stock returns in Finland. Aalto University School of Business, Bachelor Thesis.

Kuznetsova, N. V., \& Maslova, E. V. (2013). Models of corporate social responsibility. Vestnik Tomskogo Gosudarstvennogo Universiteta, 4, 22-36 (in Russian).

Li, F. (2006). Do stock market investors understand the risk sentiment of corporate annual reports? Unpublished manuscript, University of Michigan.

Li, F. (2008). Annual report readability, current earnings, and earnings persistence. Journal of Accounting and Economics, 45 (2-3), 221-247. https://doi.org/10.1016/j.jacceco.2008.02.003

Loughran, T., \& McDonald, B. (2014). Measuring readability in financial disclosures. Journal of Finance, 69 (4), 1643-1671. https://doi.org/10.1111/jofi.12162

Martinez, A. (2010). Analysts' recommendations and stock performance: An empirical study of Brazilian public companies. Available at SSRN: https://ssrn.com/abstract=1621013

Martinez-Blasco, M., Garcia-Blandon, J., \& Argiles-Bosch, J. M. (2015). Does the informational role of the annual general meeting depend on a country's legal tradition? Journal of Management \& Governance, 19 (4), 849-873. https://doi.org/10.1007/s10997-014-9294-9

Merkl-Davies, D., \& Brennan, N. (2007). Discretionary disclosure strategies in corporate narratives: Incremental information or impression management? Journal of Accounting Literature, 27, $116-196$.

Murg, M., Pachler, M., \& Zeitlberger, A. C. M. (2014). The impact of analyst recommendations on stock prices in Austria (2000-2014): Evidence from a small and thinly traded market. Central European Journal of Operations Research, 24 (3), 595-616. https://doi.org/10.1007/s10100014-0360-9

Patelli, L., \& Pedrini, M. (2014). Is the optimism in CEO's letters to shareholders sincere? Impression management versus communicative action during the economic crisis. Journal of Business Ethics, 124 (1), 19-34. https://doi.org/10.1007/s10551-013-1855-3

Pencle, N., \& Mălăescu, I. (2016). What's in the words? Development and validation of a multidimensional dictionary for CSR and application using prospectuses. Journal of Emerging Technologies in Accounting, 13 (2), 109-127. https://doi.org/10.2308/jeta-51615

Price, S. M., Doran, J., Peterson, D., \& Bliss, B. (2012). Earnings conference calls and stock returns: The incremental informativeness of textual tone. Journal of Banking and Finance, 36, 992-1011. https://doi.org/10.1016/j.jbankfin.2011.10.013

Souček, M., \& Wasserek, T. (2014). Impact of analyst recommendations on stock returns: Evidence from the German stock market. Discussion Paper No. 358, European University Viadrina Frankfurt (Oder), Department of Business Administration and Economics.

Udaltsov, V., \& Tikhonova, N. (2013). Influence of informational transparency on the cost of capital and operational efficiency of Russian public companies. Journal of Corporate Finance Research, 7 (1), 2-16. https://doi.org/10.17323/j.jcfr.2073-0438.7.1.2013.2-16

Wu, L., Hoi, S., \& Yu, N. (2010). Semantics-preserving bag-of-words models and applications. IEEE Transactions on Image Processing, 19 (7), 1908-1920.

Wu, D. D., Zheng, L., \& Olson, D. L. (2014). A decision support approach for online stock forum sentiment analysis. Systems, Man, and Cybernetics: Systems, IEEE Transactions, 44 (8), 1077-1087.

\section{Appendix A}

Table A1

Results of application of MLP Neural Network Model.

\begin{tabular}{lllllll}
\hline Neural network error & $\begin{array}{l}\text { Hypothesis } \\
1\end{array}$ & $\begin{array}{l}\text { Hypothesis } \\
2\end{array}$ & $\begin{array}{l}\text { Hypothesis } \\
\text { 1 }\end{array}$ & $\begin{array}{l}\text { Hypothesis } \\
4\end{array}$ & $\begin{array}{l}\text { Hypothesis } \\
5 \mathrm{a}\end{array}$ & $\begin{array}{l}\text { Hypothesis } \\
5 \mathrm{~b}\end{array}$ \\
\hline w/o linguistic variables & 0.492 & 10.42 & 0.47 & 0.54 & 0.67 & 0.208 \\
with linguistic variables & 0.449 & 9.45 & 0.45 & 0.45 & 0.57 & 0.196 \\
Decrease of MLP error, \% & 9 & 9 & 4 & 17 & 15 & 6 \\
\hline
\end{tabular}

Source: Authors' calculations. 


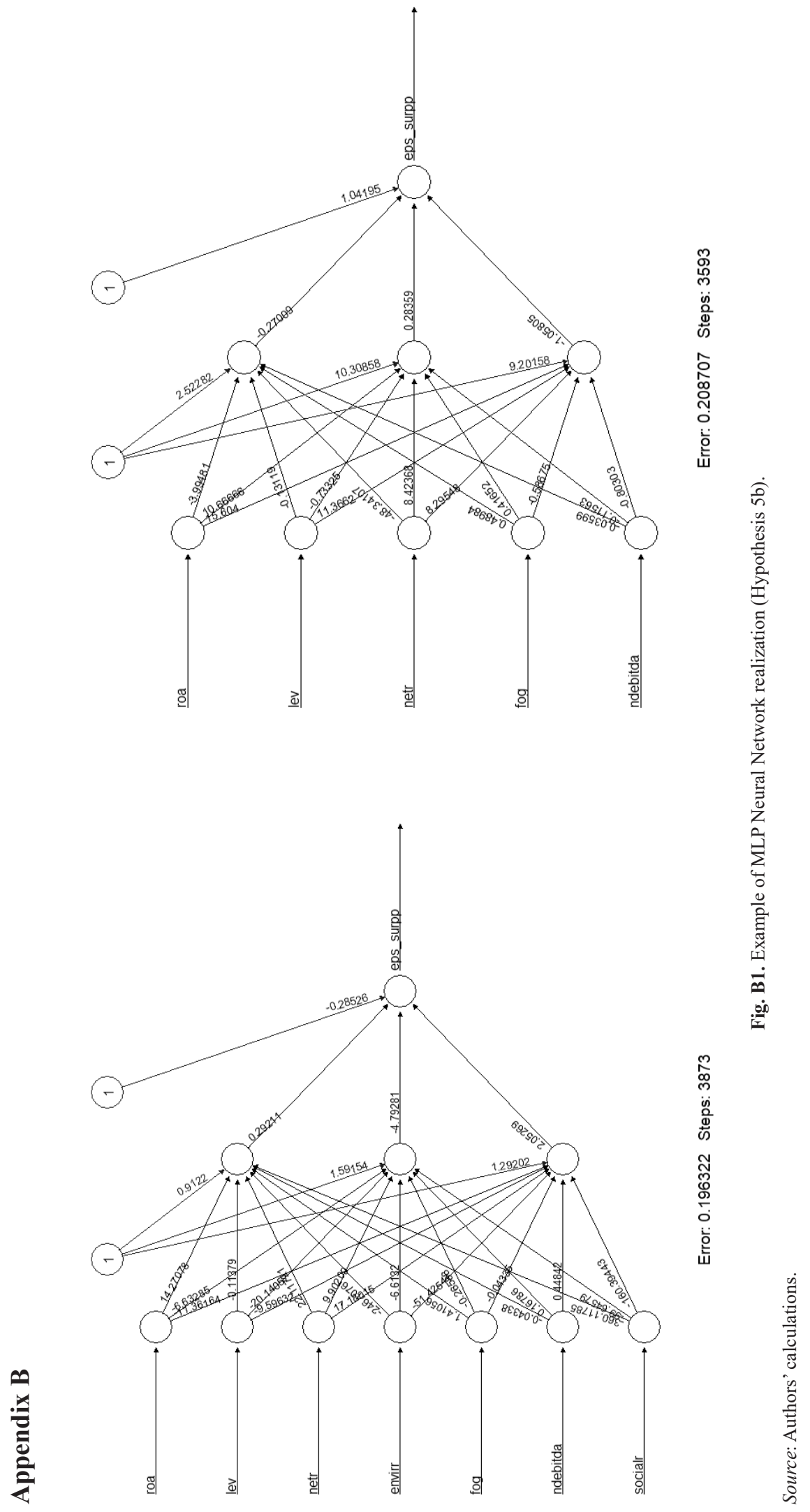

